\section{Climate costing is politics not science}

Nicholas Stern argues that today's integrated assessment models for quantifying the economic and societal impacts of climate change are inadequate (Nature 530, 407-409; 2016). We disagree with his view on the superiority of more complex models such as DSGE (dynamic stochastic computable general equilibrium) models, which purport to account for a larger class of uncertain future events.

In our view, DSGE models have proved to be ineffective for policymaking, even in simple, short-term settings of pure economics, by failing to anticipate the onset of the recent recession (see P. Mirowski Never Let a Serious Crisis Go to Waste 275-286; Verso, 2013). Three decades of social-sciences research on science and politics make it clear that cost-benefit models cannot tame policyrelevant uncertainties or promote political agreement (see, for example, D. Collingridge and C. Reeve Science Speaks to Power 3-4, 59-60; Pinter, 1986).

Models that predict higher costs of climate change might make political intervention more palatable. But prescribing models that generate more precisely quantified estimates of a desired output is a political programme, not a scientific one. Responsible research requires responsible quantification and responsible acknowledgement of uncertainty. Andrea Saltelli* Autonomous University of Barcelona, Cerdanyola del Vallès, Spain. andrea.saltelli@uib.no ${ }^{*}$ On behalf of 6 correspondents (see go.nature.com/wamqwt for full list).

\section{Europe must block hornet invasion}

Another notable omission from the European Union's list of invasive alien species that are targeted for action is the Asian yellow-legged hornet, Vespa velutina nigrithorax (see J. Pergl et al. Nature 531, 173; 2016). Since its arrival in Europe more than a decade ago, this voracious honeybee predator has also caused human deaths from its sting (see K. Monceau et al. J. Pest. Sci. 87, 1-16; 2014).

The hornet's impact is severe in Mediterranean countries, where beekeeping is a crucial source of income. Local beekeepers have their own makeshift eradication methods (such as traps of vinegar with glue), but these also kill important insect pollinators.

The species needs to be officially classified as an invader in all European countries, so that funds can be applied to its study and control. Public campaigns are essential to increase people's awareness and understanding of this threat - for example, regarding the differences between wasp species, many of which are vital for ecosystem functions and services.

We urgently need a coordinated EU plan to control this hornet invasion and to mitigate its potentially serious economic and ecological impacts. Frederico Santarém ${ }^{\star}$ Research Centre in Biodiversity and Genetic Resources (CIBIO/ InBIO), Porto, Portugal. fredericosantarem@gmail.com ${ }^{\star}$ On behalf of 5 correspondents (see go.nature.com/uao4qe for full list).

\section{Software for study design falls short}

Online software that can improve the design of animal studies is welcome, but it should not replace specialist advice (see Nature 531, 128; 2016).

Animals are complex biological systems. Their organs and tissues have variable and dynamic functions and morphology in pathophysiological conditions. This complexity calls for a holistic perspective from researchers, who can anticipate and tackle different experimental issues through all phases of a study while aiming for reduction, refinement and replacement in animal use (see www.nc3rs.org. uk/the-3rs).

Such multidisciplinary input also helps to overcome limitations in researchers' scientific scope, experience and skill sets and to improve the quality and interpretation of the results (H. A. Adissu et al. Dis. Model. Mech. 7, 515-524; 2014). David K. Meyerholz University of Iowa, Iowa City, USA.

Alessandra Piersigilli University of Bern, Bern, Switzerland. david-meyerholz@uiowa.edu

\section{Silver lining to irreproducibility}

There is room for improvement in how science is done and reported, but something can often be learned from irreproducible experiments. The situation may not be as dire as some headlines imply.

It is crucial to include caveats when citing analyses of reproducibility. For example, an often-quoted 2015 survey of factors that could improve the reproducibility of scientific results (see go.nature.com/ yxwgmb) noted that there was a low response rate to the questionnaire, a qualifier that is not always mentioned.

It is important to recognize that researchers cannot control for an unknown variable. Take a web tool for identifying unwanted 'passenger mutations' that could confound analyses of transgenic mice (T. Vanden Berghe et al. Immunity 43, 200-209; 2015). This tool arose from reports of mouse phenotypes that, unbeknown to researchers, depended on unintended mutations. This is an example of a useful resource that enhances our understanding of underlying biological phenomena and results from experiments that might otherwise be branded as irreproducible.

It is in this context that scientific societies are pushing to increase experimental rigour and reporting transparency. For instance, guidelines from the Federation of American Societies for Experimental Biology (go.nature.com/zdf89b) aim to help scientists to meet the reproducibility requirements of research funded by the US National Institutes of Health. Alyssa Ward Johns Hopkins University School of Medicine, Baltimore, Maryland, USA. Thomas O. Baldwin University of California, Riverside, USA. Parker B. Antin University of Arizona, Tucson, USA. award30@jhmi.edu

\section{Social cooperation among agnostics}

Benjamin Grant Purzycki and colleagues suggest that religion helps to explain cooperation in large societies (Nature 530, 327-330; 2016). In my view, knowledge of others' reputations forms a more stable basis for cooperation.

A network with redundant connections transmits these reputations (J. Bruggeman Social Networks; Routledge, 2008). It also avoids the strategic manipulation of information by religious entrepreneurs. Once such a cohesive network is established, religious solidarity can enhance cooperation, as can a shared enemy (J.-K. Choi and S. Bowles Science 318, 636-640; 2007) - but it is not essential.

Take the revolt against Communist regimes in 1989. These were overthrown by large-scale collective action, even though religion was negligible or subservient in those countries. Protesters united, despite each knowing only a few others (the regimes suppressed their critics). Religion is one road towards cooperation between strangers, as the experiments show, but not the only one.

Jeroen Bruggeman University of Amsterdam, the Netherlands. j.p.bruggeman@uva.nl 